\section{Vets asked valuable questions about foot-and-mouth measures}

\author{
Opposition was to a rigid policy, not to epidemiologists.
}

Sir - Your Opinion article "Lessons from an epidemic" (Nature 411, 977; 2001), which identified an apparent rift between epidemiologists and some veterinary scientists, does nothing to analyse that rift. This is unfortunate: many veterinarians have been highly praised by the UK farming community. Surely you cannot criticize veterinarians for asking whether so many animals needed to be killed, or whether vaccination should have been used, or about the sensitivity of the epidemiologists' models? These are complex questions directly involving the lives of our patients and the livelihood of our clients. It is surely our duty to question the veracity of policies that have such swingeing effects.

It is true that all disciplines must guard against myopia and welcome excellence from outside to advance their science. We have learnt the advantage of this in recent years: for example, following the United
Kingdom's BSE epidemic, chairs in veterinary epidemiology have been created in the country's veterinary schools.

The resentment to which you refer in your editorial, and which existed among some veterinary scientists, was not against the epidemiologists' models but against the rigid policy being adopted by the government following advice from these scientists, which did not allow any flexibility for local veterinary assessment of risk. To slaughter animals when there is no risk is not only immoral and unscientific, it is bad veterinary medicine.

In some hotspot areas, the UK Ministry of Agriculture, Fisheries and Food (MAFF) - now the Department of Environment, Food and Rural Affairs (DEFRA) — has lost the confidence and support of local farmers, largely because so many animals have been slaughtered unnecessarily. No national animal disease control programme will succeed without the full cooperation of the farming community.

There is plenty of evidence that veterinary scientists are and have always been willing to work with the wider scientific community, but, for successful communication, the dialogue must be in both directions. An example of where this did not occur may have been the basis for your editorial. On $23 \mathrm{March}$, a group of epidemiologists from Imperial College London did not endear themselves to any of the stakeholders in the foot-and-mouth crisis when they refused to release the details of their modelling work until it had been published on 12 April (Science 292, 1155-1160; 2001). Fortunately, other epidemiology groups from Edinburgh, Cambridge and the Veterinary

Laboratories Agency did make full details of their work and their opinions immediately available.

We accept that there are lessons to be learnt from this outbreak and we are keen to learn them. We are fully paid-up members of the wider scientific community and will continue to cooperate outside our profession, particularly in the control and prevention of animal disease. R. G. Eddy

Royal College of Veterinary Surgeons, Horseferry Road, London SW1P 2AF, UK

\section{Always a role for debate between disciplines}

Sir - The Opinion article "Lessons from an epidemic" (Nature 411, 977; 2001) fills me with concern for the future of science and public scientific debate. It would appear that you believe veterinary scientists should not be allowed to question the scientific conclusions reached by another discipline. The implication that these scientists are resentful at the leading role played by epidemiologists in the UK foot-and-mouth-disease crisis is misleading and untrue.

Surely there is always justification for scientific debate, questioning and investigation as to whether the output of the science is valid, sensitive and appropriate for the situation in which it is being used? In the case of foot and mouth it seems very appropriate for models based on mathematical formulae to be commented on by those involved in the control of disease. The questions posed - about the use of vaccination, the sensitivity of the epidemiological models and whether so many animals need to be killed — are of interest to the community at large.

Your Opinion article suggests that scientific questioning of those in one specialist area by those in another is not permissible, whereas in my opinion this is quite justified and indeed follows the concepts laid down by Lord Phillips in the UK BSE inquiry. Equally, I have no doubt that models must be used even more in future, although again it must be recognized that there are various types of models producing different results for use in different circumstances. This requires that mathematical modellers, the veterinary profession and other advisers work together as a team to produce the best advice and a range of options.

Economists also need to be included, as in many cases their role is equally important in determining the most cost-effective method for control of outbreaks such as the foot-and-mouth epidemic.

I echo your conclusion that various scientific disciplines must work closely together in future. Each will bring its own expertise, the sum of which will produce far better results than each alone, and enable those determining policy to receive the best advice. In the case of foot and mouth, I facilitated the rapid provision of the necessary data and I would hope that we can build on this in the future.

Nevertheless, all scientists, whatever their discipline, have the right to question the conclusions of others.

\section{J. M. Scudamore}

State Veterinary Service, Department for Environment, Food and Rural Affairs,

IA Page Street, London SW1P 4PQ, UK e-access

The debate continues at i http://www, nature. com/nature/debates/e-access/index.html.

\section{Beneficiaries should pay}

Sir - The debate about free access to publications in Commentary, Correspondence and your website (see www.nature.com/nature/debates/e-access/ and, for example, Nature 411, 521-522; 2001 ) is valuable. I have not, however, seen taken into account the point that despite the bias introduced by the publishor-perish ethos - research publication contributes an 'external benefit' to appointments committees, grant-awarders and those evaluating research careers, which could not be obtained in any other way, or, probably, at any price. This means that the activities of these organizations are indirectly subsidized by subscribers to science journals.

External benefits can and should be paid for. It would be a reasonable act of good faith if these committees, grantawarders and other organizations were to make a contribution to an academic library every time they took a decision that depended necessarily on the journal system these libraries finance. Can a mechanism be found to implement this suggestion?

Henry Nathan

Scientia, 12 rue Jacob, 75006 Paris, France 